\title{
Isolated fourth ventricle haemorrhage: "think beyond intracranial source" unusual presentation of lumbosacral spine arteriovenous malformation presentation
}

\author{
Naresh Panwar ${ }^{1}$, Manish Agrawal ${ }^{2}$, \\ Ghanshyam Agrawal' ${ }^{2}$ V. D. Sinha ${ }^{2}$ \\ 1 Department of Neurosurgery, Fortis Escorts Heart \& Research \\ Institute, New Delhi, INDIA \\ 2 Department of Neurosurgery, SMS Medical College, \\ Jaipur, Rajasthan, INDIA
}

\begin{abstract}
Spinal arteriovenous malformations (SAVMs) are rare vascular lesions and account for about $4 \%$ of primary intraspinal masses. Since SAVMs can involve any location along the spinal column and produce a host of different problems, the symptoms are extremely variable. There are few reports of simultaneous cerebral SAH and intraventricular hemorrhage (IVH) following rupture of a spinal AVM (SAVMs). Herein, we present a rare case of Lumbo Sacral spine arteriovenous malformation, which clinically manifests as sudden onset of severe headache and vomiting due to isolated fourth ventricle Hemorrhage (IVH) without cerebral subarachnoid hemorrhage.
\end{abstract}

\section{INTRODUCTION}

Being a rare category, spinal vascular malformations (SAVMs) account for about $4 \%$ of primary intraspinal masses (3). Rosenblum and coworkers described two major types of spinal AVM intradural versus dural on the basis of location of nidus: intradural versus dural. Intradual AVMs were classified as intramedullary and dural AVFs (Arteriovenous fistula). They usually present with pain, numbness, and weakness, loss of bowel/bladder control, incoordination, and impotence is few of the issues. In majority of cases SAVMs first come to medical attention by bleeding - this usually presents as acute, severe back pain, followed by sudden onset weakness, numbness, incontinence; severity ranges from no neurologic dysfunction to complete paralysis, depending on location and extent of bleeding. The natural history of spinal vascular malformations (SAVMs) is unpredictable and varies from acute subarachnoid hemorrhage of spine to venous congestion of cord.

As far as cranial manifestation of SAVMs concerns cerebral sub arachnoid hemorrhage (SAH) has been reported in English literature, and seems to be caused by rupture of same intra ventricular bleed due

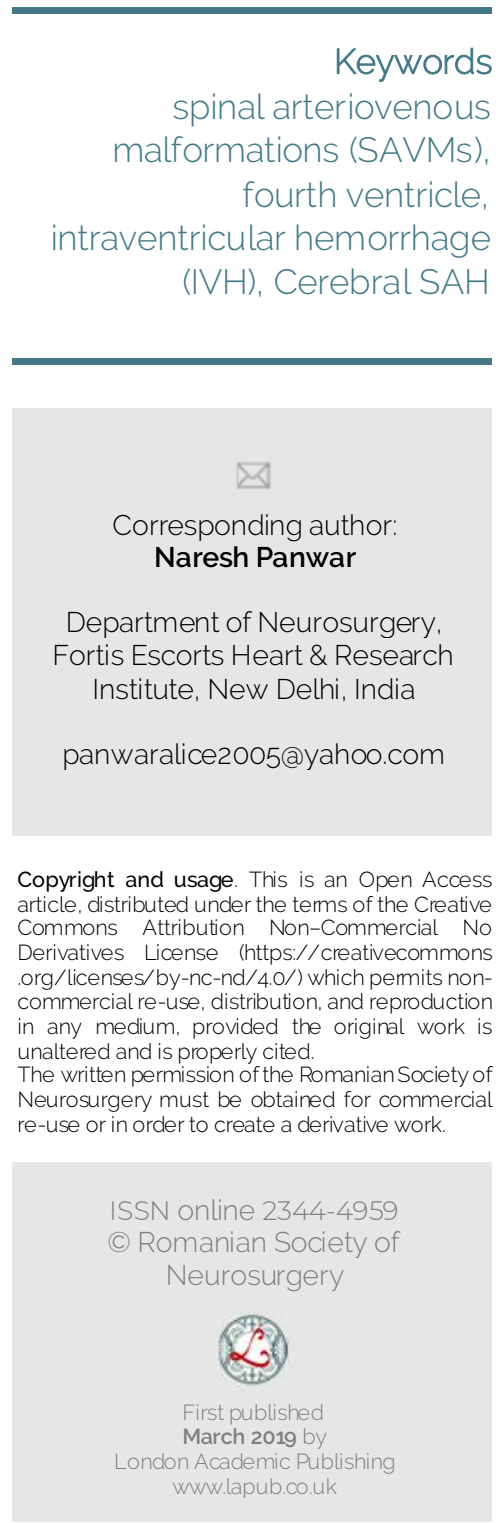


to SAVMs has been reported four times in last decade. We believe this to be the first reported case of a Lumbosacral SAVMs presenting as isolated fourth ventricle hemorrhage (IVH.) We also need a kind attention regarding left lower limb swelling; it might be due to raised venous pressure which was resolved spontaneously after definitive surgical management of SAVMs.

\section{CASE REPORT}

A twenty-year-old adult male experienced sudden onset severe headache associated with episodes of vomiting in a morning during defecation, which was preceded by severe lower back pain. There was no history or signs of trauma, no previous history of back pain, radiculopathy, or myelopathy were reported. On examination it was revealed that patient was conscious, oriented and without any focal neurological sign. He had left lower limb swelling which was misdiagnosed as varicose vein of limb and was operated 6 months back for same, but swelling did not subsidize.
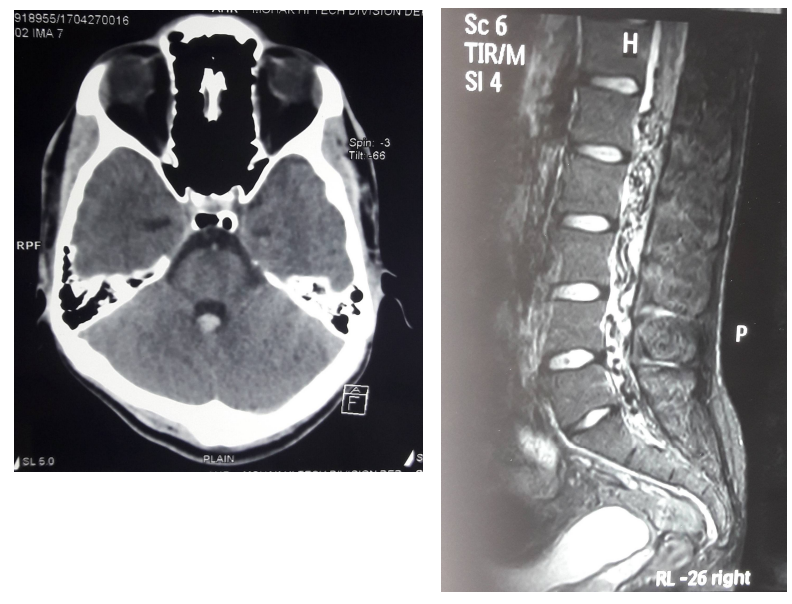

\section{DISCUSSION}

Spinal arteriovenous malformation (SAVM) is a rare, abnormal tangle of blood vessels on, in or near the spinal cord and account approximately $10 \%$ of CNS vascular malformations in all age groups. These lesions are directly supplied by radicular arteries and drained by spinal cord veins, although dural supply can occur as with dural arteriovenous fistulas. $(3,7)$

On the basis of location these lesions are divided into either intradural or extradural, and intradural further subdivided into intramedullary or extramedullary. Most are thoracolumbar, posterior, and outside the cord (extramedullary). The rest are cervical or upper thoracic and often inside the cord
Non contrast computed tomography (CT) of head was done, which showed fourth ventricle hemorrhage with concomitant sparing of bilateral lateral and third ventricle, all cisterns were seen normally and had no evidence of cisternal bleeding and sub arachnoid hemorrhage (FIGURE 1). Magnetic Resonance imaging (MRI) brain, CT Angiography brain and digital subtraction angiography (DSA) brain did not reveal any intra cranial source of bleeding, but MRI Lumbo sacral region (FIGURE 2) and spine Digital subtraction angiography revealed spinal perimedullary AVM (SAVMs) at L1 to S1 level (conus medullaris) with feeding artery aneurysm and venous drainage from spinal vein to perimedullary vein and extending cranially(figure-3). The lesion was treated surgically as cauterization and disconnection of the vein. Till the writing of this report 12 month follow up has been completed and he is neurologically intact and most importantly lower limb swelling subside within first month of surgery (FIGURE 4).
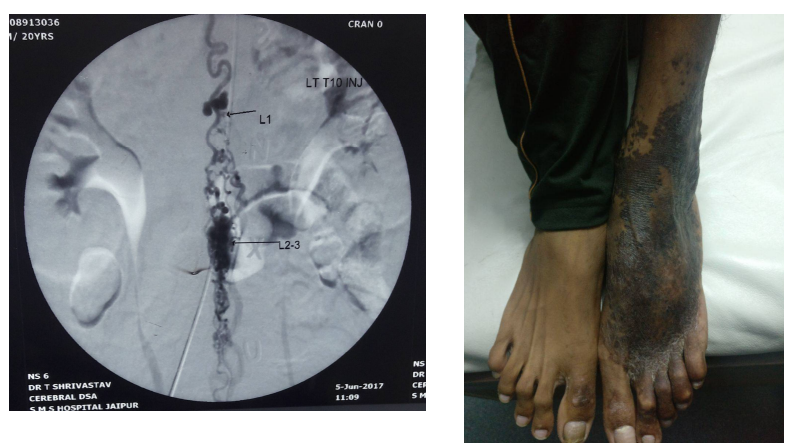

FIGURE 1. NCCT Head showed small hyper density in 4th ventricle suggestive of recent intraventricular bleed.

FIGURE 2. MRI L S Spine T2 weighted with GRE shows multiple flow void in intradural lumbo-sacral region extending from L1 to S1 levels. Subtle enhancement is seen in blood vessel with slow flow. No enhancement is seen with blood vessel with high flow suggestive of spinal dural AVF.

FIGURE 3. Spinal DSA showing Lumbo-sacral dural AVF with pre nidal aneurysms with feeder from left $\mathrm{T} 10$ rediculomeningeal artery.

FIGURE 4. Swelling left leg, which reduced drastically after treating primary pathology along with hyper pigmentation on dorsum of foot.

(intramedullary). AVMs may be small and localized or may affect up to half the cord. $(3,6)$

In majority of patients the ultimate fate of spinal AVM is progressive neurological deficit in terms of sensory, motor or bladder/ bowel involvement. In 
some situation rarely, high cervical AVMs rupture into the subarachnoid space, causing subarachnoid hemorrhage with sudden and severe headache, nuchal rigidity, and impaired consciousness (4). The natural history of SAVMs is characterized by venous congestion causing progressive neurological deficits in majority of patients. $(3,8)$

In the literature, a thoracolumbar SAVMs presenting with both SAH and IVH appears to be a rare occurrence. Although there are few reports of concomitant cerebral SAH and intraventricular hemorrhage (IVH) following rupture of a spinal SAVMs $(2,3,5)$. There have been three case reports of SAVMs presenting in the adult population and two in pediatric age group with intraventricular hemorrhage (IVH) exist in the literature. In both groups, the clinical, radiographic, and surgical findings suggested that the SAVM was the source of the hemorrhage.

In 1999 P Bazro et al reported first case of intraventricular hemorrhage attributed by the rupture of conus medullaris AVM in a young patient. (1). ES Marlin et al reported a case of intraventricular hemorrhage in both lateral, third and fourth ventricle in a 2-year-old female child caused by rupture thoraco lumber SAVMs, who died in next few days probably due to re rupture. (3). Recognition of such cases in future may allow earlier diagnosis and treatment before catastrophic re hemorrhage. Masanori et al reported another case who presented with intraventricular hemorrhaging (IVH) into the fourth and third ventricles that was caused by a cervical intramedullary arteriovenous malformation. (4)

To the best of our knowledge, this is the first case report of an adult patient in whom initial imaging demonstrated isolated fourth ventricle hemorrhage (IVH) without Sub arachnoid hemorrhage (SAH) secondary to a ruptured low lumbosacral SAVMs. Till the date only five cases of Intraventricular hemorrhage is reported in literature.

TABLE 1. Patients presenting with IVH caused by rupture of Spinal AVMs

\begin{tabular}{|c|c|c|c|c|c|}
\hline S.NO. & Author(s) & Year & Age/sex & Ventricular hemorrhage & Location of spinal AVM \\
\hline 1 & H Baharvahdat et al (2) & 2016 & $\begin{array}{l}48 \\
\text { Year/Male }\end{array}$ & $\begin{array}{l}\text { B/L Lateral, Third \& } \\
\text { fourth ventricle and SAH }\end{array}$ & Conus Medullaris AVM \\
\hline 2 & E. S. Marlin et al. (3) & 2014 & $\begin{array}{l}2 \text { Year/ } \\
\text { Female } \\
\text { child }\end{array}$ & $\begin{array}{l}\text { B/L Lateral, Third \& } \\
\text { fourth ventricle }\end{array}$ & $\begin{array}{l}\text { Thoraco lumber Spinal } \\
\text { AVM }\end{array}$ \\
\hline 3. & Kenning. T.et al (5) & 2009 & $\begin{array}{l}1 \text { Year } 2 \\
\text { month } \\
\text { /female } \\
\text { childe }\end{array}$ & $\begin{array}{l}\text { B/L Lateral, Third \& } \\
\text { fourth ventricle and SAH }\end{array}$ & $\begin{array}{l}\text { Thoraco lumber spinal } \\
\text { perimedullary AVM }\end{array}$ \\
\hline 4 & Masanori Ito et al (4) & 2007 & $\begin{array}{l}33 \text { Year } \\
\text { /male }\end{array}$ & Third \& fourth ventricle & $\begin{array}{l}\text { Cervical intramedullary } \\
\text { spinal AVM }\end{array}$ \\
\hline 5 & P Barzó et al (1) & 1999 & $\begin{array}{l}28 \text { Year } \\
\text { /male }\end{array}$ & $\begin{array}{l}\text { B/L Lateral, Third \& } \\
\text { fourth ventricle }\end{array}$ & Conus medullaris AVM \\
\hline 6 & Present case & 2017 & $\begin{array}{l}20 \\
\text { Year/male }\end{array}$ & Isolated fourth ventricle & $\begin{array}{l}\text { Lumbo sacral Spinal } \\
\text { AVM }\end{array}$ \\
\hline
\end{tabular}

Although to kept Lumbosacral SAVMs as a differential diagnosis for isolated spontaneous fourth ventricle IVH is beyond the imagination particularly in adult patient, where the distance between the bleeding source and presenting site is significant. The present case suggests that MRI of 
the entire spine with dedicated blood detected sequence GRE \& SWI should be considered if cranial angiography does not reveal a source. $(2,3)$. There must be some possible hypothesis of raised venous pressure behind the swelling of left leg due to SAVMs being wrongly operated for varicocities. So, such possibilities in these cases should also be considered.

\section{ConCLUSIONS}

The case reported raises necessity of complete spinal neuraxis evaluation especially in young group of patients presenting with angiographically negative intraventricular hemorrhage. Evaluation for thoracolumbar spinal vascular malformations must be included in the initial work up. A whole spinal workup should be considered, when bleeding from intracranial origin is carefully excluded.

This is reminder to treating neurosurgeon along with concern medical fraternity as neurointerventionalist for careful consideration this rare differential and it has to be kept in mind that presentation can varied from head to toe.

\section{ABBREVIATIONS}

$\mathrm{IVH}$ - Intra Ventricular hemorrhage

SAH - Sub arachnoid hemorrhage

SAVM - Spinal arterio vascular malformation

DAVF - Dural arterio venous fistula

MRI - Magnetic Resonance imaging (MRI)

DSA - Digital substraction angiography

SWI -Susceptiblity weighted imaging

\section{REFERENCES}

1. Barzó $P$, Vörös E, Bodosi M: Intraventricular hemorrhage as a false localizing sign of a thoracolumbar arteriovenous malformation: case report. Surg Neurol 51:430-434, 1999.

2. H Baharvahdat et al. Diffuse Subarachnoid and Intraventricular Hemorrhage as the Presenting Sign of a Conus Medullaris Arteriovenous Malformation: Case Report Neurol Neurochir Pol. 2016 Nov - Dec; 50(6):487490.

3. ES Marlin et al Thoracolumbar Spinal Vascular Malformation as a Rare Cause of Isolated Intraventricular Hemorrhage:J Neurosurg Pediatr 14 (1), 12-15. 2014.

4. Masanori Ito et al.Spinal intramedullary arteiovenous mal formationdraining into petrosal and straight sinusresulting in intraventricular hemorrhage: Acase report .spinal surgery 21 (1); 35-41,2007.

5. Kenning T], Deshaies EM, Adamo MA, Waldman JB, Boulos AS: Onyx embolization of a thoracolumbar perimedullaryspinal arteriovenous fistula in an infant presenting with subarachnoid and intraventricular hemorrhage. Case report. J Neurosurg Pediatr 3:211-214, 2009.

6. Kim LJ, Spetzler RF: Classification and surgical management of spinaarteriovenous lesions: arteriovenous fistulae and arteriovenous malformations. Neurosurgery 59 (5 Suppl 3): S3-195-S3-201, 2006.

7. Niimi Y, Setton A, Berenstein A: Spinal dural arteriovenous fistulae draining to the anterior spinal vein: angiographic diagnosis.Neurosurgery 44:999-1004, 1999.

'8. Yaşargil MG, Symon L, Teddy PJ: Arteriovenous malformations of the spinal cord. Adv Tech Stand Neurosurg 11:61-102, 1984. 